\title{
Safety Distance of Shotcrete Subjected to Blasting Vibration in Large-Span High-Speed Railway Tunnels
}

\author{
Ao Li (D), Dingli Zhang, Qian Fang $\mathbb{D}$, Jiwei Luo, Liqiang Cao, and Zhenyu Sun \\ Key Laboratory for Urban Underground Engineering of the Education Ministry, Beijing Jiaotong University, \\ Beijing 100044, China \\ Correspondence should be addressed to Ao Li; 15115279@bjtu.edu.cn
}

Received 16 May 2019; Revised 4 August 2019; Accepted 28 August 2019; Published 14 October 2019

Academic Editor: Mahmoud Bayat

Copyright (c) 2019 Ao Li et al. This is an open access article distributed under the Creative Commons Attribution License, which permits unrestricted use, distribution, and reproduction in any medium, provided the original work is properly cited.

The drill and blast method is widely used in constructing tunnels in rock. Unfortunately, blasting vibration can damage newly performed shotcrete layers which are major support structures to stabilize surrounding structures. Therefore, investigation of the influence of blasting on shotcrete and determining reasonable distance between blasting work face and shotcrete position is of great importance. In this paper, a large-span tunnel excavated by drill and blast method acting as a high-speed railway station has been investigated. Blast vibration in the tunnel was recorded using microseismic monitoring technique. Empirical prediction equations for peak particle velocity (PPV) were obtained through regression analysis based on the obtained monitoring data. The attenuation law of tensile stress imposed on shotcrete layer due to blasting and bond strength of shotcrete-rock interface was also investigated. Minimum safety distance between shotcrete and blasting positions was calculated based on bond failure criterion. Evolution law considering different factors including blasting charge, rock mass class, and setting time of shotcrete was also obtained, which could be applied to determine blast charge shotcrete arrangements for tunnel constructions in future. The obtained results showed that the safety of shotcrete could be ensured and shotcrete falling off the rock could be prevented under current blast constructions.

\section{Introduction}

Shotcrete, or sprayed concrete, is a construction technique in which concrete is shot at high velocity onto a suspended surface. Performing shotcrete provides additional benefits such as excellent bonding with most substrates, particularly on those with complex forms or shapes, and rapid and instant capabilities. These advantages allow shotcrete to be widely used as a construction technique in tunnels excavated by the drill and blast method [1-3]. Usually shotcrete and blasting operations are performed alternately, and the main function of shotcrete is to provide a safe working environment for workers and facilitate subsequent operations of support construction such as installing metal meshes and bolts $[4,5]$. Therefore, high capability of projecting shotcrete on rock surfaces is vital to the safety of workers and the function of tunnels [6].

Using the drill and blast method, tunnels in rock are excavated by blasting large quantities of explosives. These detonations create stress waves that transport energy through rock and surrounding structures. Since shotcrete is applied near the blasting face, it is vulnerable to stress waves created by large-scale blasting in tunnels. Practically, the next blasting cycle should be performed after the final setting strength of shotcrete is reached and a certain distance should be kept between blasting and shotcrete positions. However, if shotcrete is exposed to vibrations at early ages, while it is still in hardening stage, cracks and sheddings may occur in the structure adversely affecting the function of hard concrete, even causing the failure of the whole support structure [7]. To ensure the security of shotcrete, the effect of blastinduced vibrations should be investigated and safety distance threshold from blasting work face, where shotcrete can withstand blast vibration, should be determined $[8,9]$, as shown in Figure 1.

Blast-induced vibrations are usually characterized by two important parameters, peak particle velocity (PPV) and blast predominate frequency $(f)[10,11]$. Researchers have shown that the failure of the inner structures of rock masses is caused by stress waves whose PPV value depends on the 


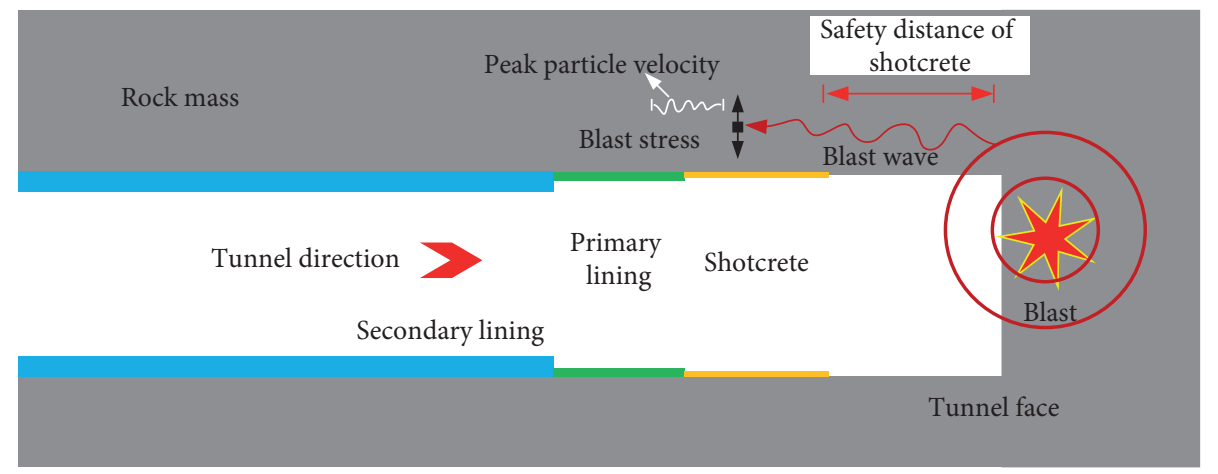

FIGURE 1: Schematic diagram of safety distance of shotcrete subjected to blast vibration in a tunnel.

dynamic stress and strain of the rock mass $[12,13]$. Therefore, once the course of vibration is recorded, its potential consequences can be assessed.

Some researchers have investigated the effect of vibration caused by blasting on shotcrete through in situ tests [4-6, 14-16]. Blast vibration responses (especially PPV) of rock and shotcrete are measured with accelerometers and velocimeters placed on rock surfaces and at the floor or arch waist of tunnel. However, because the sensors are in incomplete contact with rocks, vibration signals are easily disturbed and only vibration on the rock surface is measured, but not on the shotcrete because the shotcrete had not been constructed yet when blasting vibration monitoring [6]. Meanwhile, the damage of rock mass at the crown is enormous compared with rock mass at the floor or arch waist because of the double effects of blasting and gravity of rock mass. Therefore, the vibration monitoring inside the rock and at the tunnel crown is vital for the security of shotcrete. In general, the common approach to investigate wave propagation characteristics is by field monitoring data regressed by empirical equations such as Sadovskii equation [17], which is widely used in blasting operations in China [18]. The Sadovsky equation can describe the attenuation of maximum blast vibration velocity (or PPV) which depends on blasting charge $(Q)$, geotechnical parameters ( $K$ and $\alpha$ ), and the distance between blasting work face and monitoring point $(R)$. In evaluating the safety of the blast vibration of shotcrete, PPV and dominant frequency should be considered simultaneously. Different countries have different criteria for blast vibration to protect fresh concrete $[6,11]$. By comparing with allowed values of PPV, security status can be evaluated and the safety distance of shotcrete can be determined.

Numerical simulations have also been applied in the prediction of vibration damage to shotcrete due to tunnel explosions based on elastic stress wave theory and structural dynamics $[7,10,19,20]$. Safety distance thresholds for shotcrete can be evaluated based on different criteria such as maximum tensile stress and Mohr-Coulomb criteria. Among different shotcrete criteria, maximum velocity components or tensile stresses should be compared with allowed values to decide whether shotcrete would fail or not. Therefore, critical distance between blasting work and shotcrete can be determined beyond which shotcrete can withstand blasting vibration. There are only a few theoretical solutions which mainly adopt ray-theoretical method and present mathematical laws to predict PPV based on different blast designs and rock parameters [13]. Based on the allowed value of vibration velocity, safety requirements including blasting parameters and shotcrete distance from blasting point can be determined. On the whole, for the numerical simulations and theoretical solutions, their accuracies depend on related input parameters which are difficult to determine and commonly need to be verified according to the field test results.

In general, the safety of shotcrete subjected to blast vibration is affected by blast parameters, geological characteristics, and distance between blast and observation points [21]. It can also be determined by the failure criteria of shotcrete. Research has shown that the failure of shotcrete is mainly due to the yielding of shotcrete-rock interface rather than the destruction of shotcrete itself [22]. This paper aims to determine the safety distance of shotcrete based on the bond failure of shotcrete-rock interface subjected to blasting in tunnel excavations. In this paper, an analysis method based on both in situ tests and theoretical solutions has been used, an approach similar to that in $[5-7,22]$ but here applied for different geological conditions and tunnel geometries. The monitoring scheme with symmetry testing points inside the rock has been carried out for blast vibration monitoring in the large-span tunnel. Revealing the failure mechanism of shotcrete is of great significance and can ensure the security of the structure. The research methodology is as follows.

Firstly, an empirical equation is derived for PPV using regression analysis based on in situ monitoring data. Secondly, the tensile stress imposed on shotcrete-rock interface is calculated through multireflections and transmissions solutions of blast stress wave. Thirdly, adhesive strength of the bond between shotcrete at different ages and rock under various rock conditions is put forth. Then, safety distance is derived based on the bond failure criterion of shotcrete-rock interface. Finally, some detailed guidelines are proposed for young shotcrete considering rock mass class and shotcrete ages.

\section{Site Description and Field Monitoring}

2.1. Project Overview. Beijing-Zhangjiakou high-speed railway is about $174 \mathrm{~km}$ long with 10 stations and is 
considered as a crucial link for 2022 Winter Olympics to be held in Beijing and Zhangjiakou in Hebei province (Figure 2). Beijing-Zhangiiakou high-speed railway is under construction and is expected to be completed by the end of 2019 and reduces travel time between Beijing and Zhangjiakou from three hours to only one hour.

Badaling Great Wall Station (from DK67+815 to DK68 +285$)$ is an underground station located below the Guntiangou parking lot in Badaling scenic area. The overburden depth of the station is $102 \mathrm{~m}$ and is the deepest highspeed railway station in the world. The station has a 3-level underground structure including platform, hall floor, and equipment floor levels. At platform level (Figure 3), the main structure of the station consists of three tunnels which integrate into a triple-arch tunnel. The large-span transition tunnel (from DK68 + 285 to DK68 + 448) with 5 different cross sections is located between the station and standard double-track single-tube tunnel, as shown in Figure 4. The maximum excavation span of the large-span transition tunnel is $32.7 \mathrm{~m}$ with an excavation area of $494.4 \mathrm{~m}^{2}$. As the traffic tunnel with the widest excavation span and largest excavation section area in the world, its construction is extremely difficult and has high safety risks [23].

Figure 5 shows the typical geological profile of the largespan transition section tunnel from DK68+285 to DK68 +448 along the direction of Zhangjiakou. The tunnel passes through a small (F1) and a large (F2) fault and fracture zone. Fault F2 intersects the tunnel at DK68 +260-300 filled by a compresso-shear fracture with the attitude of $263^{\circ} \angle 86^{\circ}$. Rock masses are generally complete with major 3-4 sets of largely developed joints. Groundwater in the area is bedrock fissure water with normal yield of about $2400 \mathrm{~m}^{3} / \mathrm{d}$. Table 1 shows rock mass classification obtained according to Chinese classification basic quality (BQ) system and properties of large-span tunnel.

2.2. Microseismic Monitoring Layout. Microseismic monitoring technology, an advanced and effective method for monitoring tunnel stability, has been employed in many tunnels [24]. According to this method, the energy released during blasting operations is acquired by geophones spread in certain patterns and analyzed using earthquake seismology and seismic migration techniques. The use of microseismic monitoring allows operators to better understand quantitative data on the location, level, and size of blasting [25]. Symmetric monitoring points inside the large-span tunnel were used for blast vibration monitoring.

2.2.1. Monitoring System. The blasting microseismic monitoring hardware system was composed of vibration sensors, data collector, GPS clock synchronizer, fiber optic converter, and data processing system. Figure 6 shows the diagram of microseismic monitoring system network. Single- and threecomponent vibration geophones with high sensitivity $(200 \mathrm{~V} / \mathrm{m} / \mathrm{s})$ and broad range of target acceptance frequency $(4.5-1000 \mathrm{~Hz})$ as well as a 24-channel data collector with high resolution (32 bit $\mathrm{A} / \mathrm{D}, 24$ bit $\mathrm{A} / \mathrm{D}$ ), high sampling rate $(2000 \mathrm{~Hz})$, high triggering accuracy $(+1 \mu \mathrm{s})$, and low background noise $(<0.15 \mu \mathrm{V}$ RMS@2 ms, 0.09 $\mu \mathrm{V}$ RMS@ $2 \mathrm{~ms}$ ) were adopted. Microseismic collector and monitoring terminal were connected with optical fiber to achieve remote view and control. Time accuracy was guaranteed with the combination of GPS clock synchronizer and optical fiber network.

2.2.2. Monitoring Points. Two monitoring sections, DK68 + 290 (Section 1) and DK68 + 440 (Section 2), were selected for the installation of sensors in the tunnel. Three boreholes were drilled in each section, each about $12 \mathrm{~m}$ deep. In each borehole, a three-component sensor $\left(1^{*}, 2^{*}\right.$, and $\left.3^{*}\right)$ was installed at the depth of $12 \mathrm{~m}$, and a single-component sensor $\left(4^{*}, 5^{*}\right.$, and $\left.6^{*}\right)$ was placed at about $3 \mathrm{~m}$ away from hole entrance coupled using cement grouting (Figure 7). Figure 8 shows monitoring sensors and their installation diagram.

\section{Analysis of Blast Velocity and Stress Based on Microseismic Monitoring Data}

Blasting vibration can be evaluated based on vibration velocity, acceleration, frequency, etc. PPV and $f$ are often applied for this purpose. PPV is defined as the maximum motion velocity of a particle on or in the rock induced by the passage of blast vibration waves [26]. Moment magnitude $\left(M_{\mathrm{w}}\right)$ quantitative measure of an earthquake's magnitude (or relative size) is designed to produce more accuracy accounting for the total energy released by an earthquake or blasting. To fully record the motion, it is necessary to measure three perpendicular longitudinal $(x)$, transverse $(y)$, and vertical $(z)$ components. The peak values of individual components rarely occur at the same instant [27].

3.1. Monitoring Results. Microseismic monitoring data of blast vibration including PPV with three perpendicular components, the blasting charge $(Q)$, the distance from the blasting point to the measuring point $(R)$, the predominate frequency $(f)$, and moment magnitude $\left(M_{\mathrm{w}}\right)$ were measured.

Monitoring results for 23 sets of blasting in the largespan tunnel were collected. One set of monitoring data in the tunnel is shown in Table 2, where PPV-X, PPV-Y, and PPV$Z$ are the maximum values of velocity vectors along longitudinal, transverse, and vertical directions, respectively.

3.2. Empirical Equation of PPV. Explosion-induced vibration features are mainly influenced by blasting source and geological factors [28]. Several empirical relationships have been suggested by different investigators to describe the attenuation of blast vibration [10-13]. It is hard to determine which empirical formula is the best one, because the fitting errors of different empirical formulas cannot be avoided. The Sadovsky equation covers two site-specific parameters considering the effects of blasting and geology, and they can be determined by regression analysis [17]. Therefore, the Sadovsky equation is most widely used to study the attenuation of blast vibration in China [18], that is, 


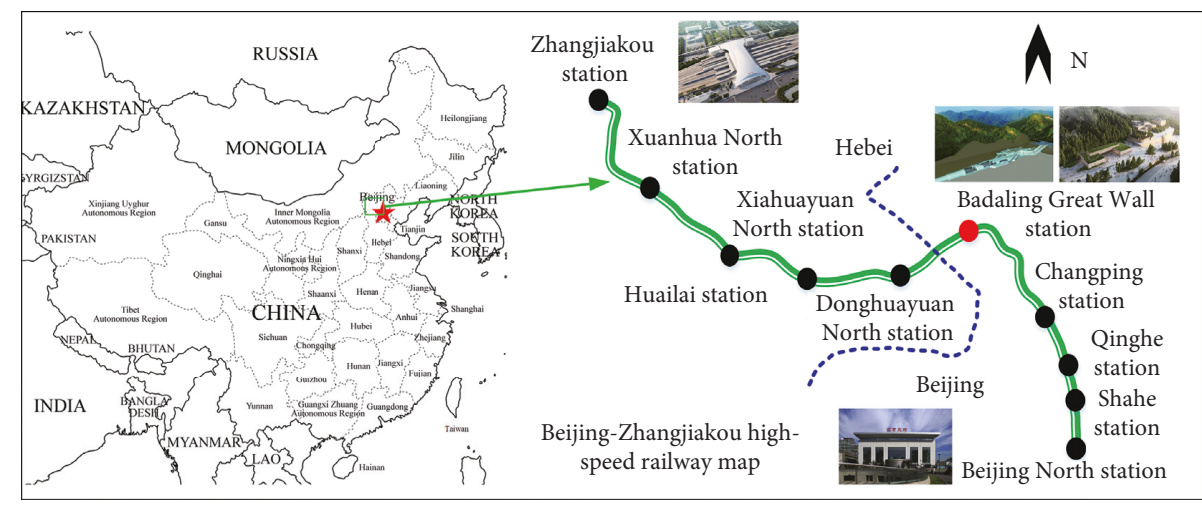

FIgURE 2: Map of Beijing-Zhangjiakou high-speed railway.

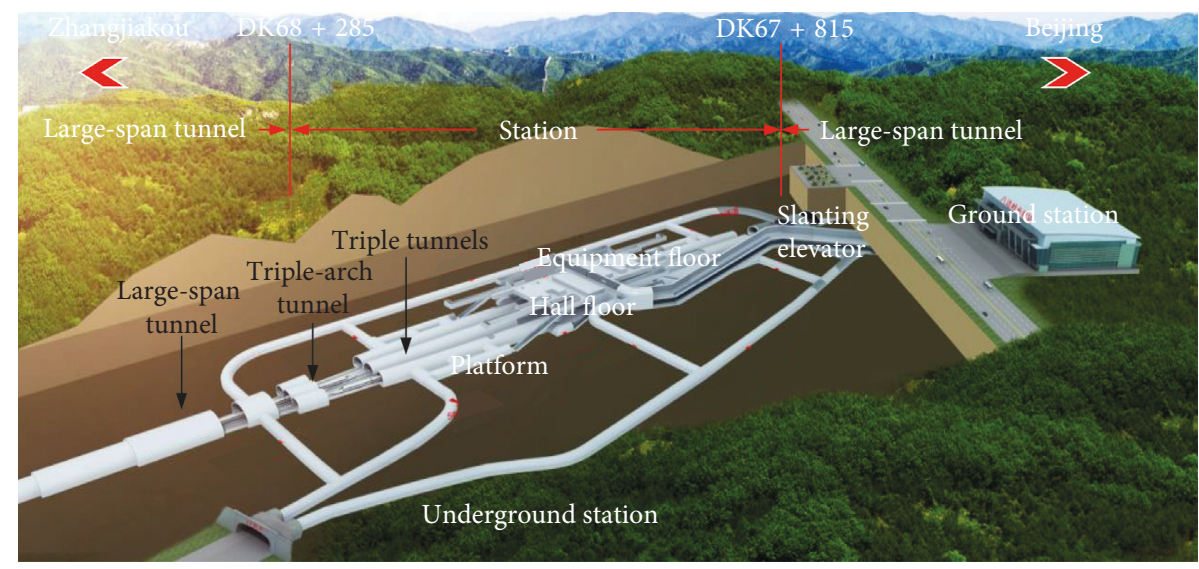

Figure 3: Design sketch of Badaling Great Wall Station.

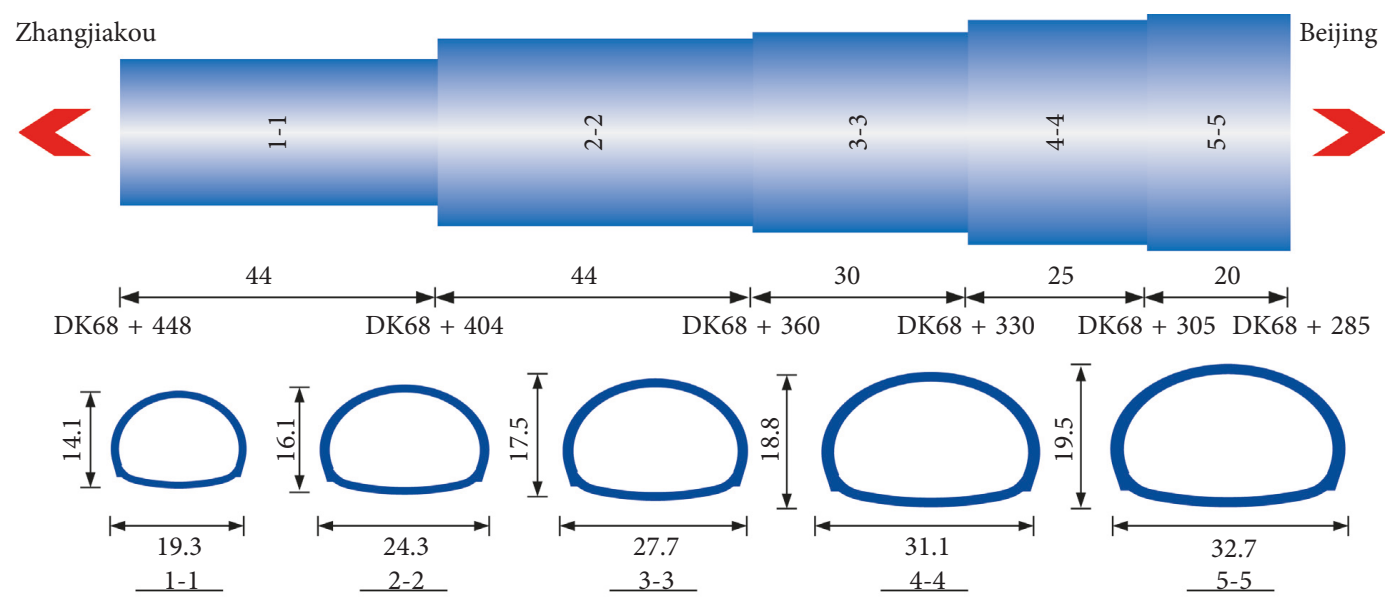

Figure 4: Layout and cross section of large-span tunnel (unit: m).

$$
V=K\left(\frac{\sqrt[3]{Q}}{R}\right)^{a}
$$

where $V$ is the particle vibration velocity $(\mathrm{mm} / \mathrm{s})$.

Equation (1) can be transformed into the following equation:

$$
\ln V=\ln K+a \times \ln \left(\frac{\sqrt[3]{Q}}{R}\right)
$$

Substituting $Y=\ln V, b=\ln K$, and $X=\ln \left(Q^{1 / 3} / R\right)$ into equation (2), the following linear equation can be obtained:

$$
Y=b+\alpha X
$$




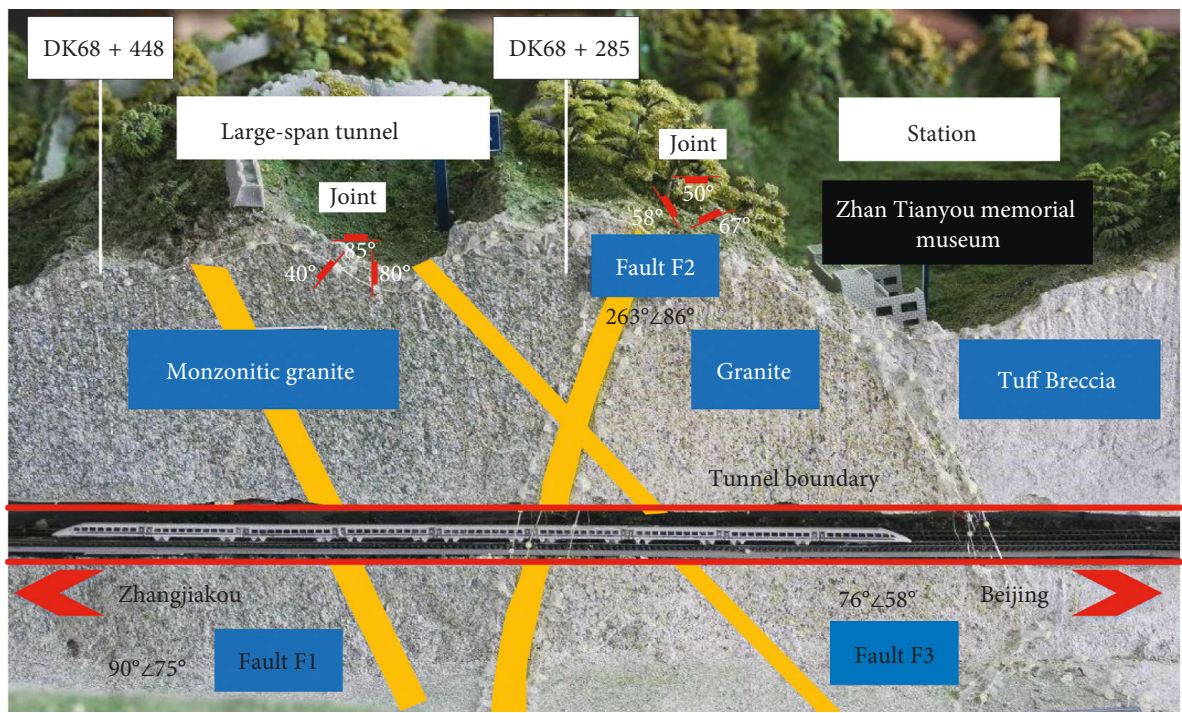

FIGURE 5: Geological profile of large-span tunnel long the direction of Zhangjiakou.

TABLE 1: Rock mass classification and properties of the large-span tunnel.

\begin{tabular}{lccccc}
\hline Mileage & Rock mass classification & Quality & $V_{\mathrm{p}}(\mathrm{m} / \mathrm{s})$ & $\rho\left(\mathrm{kg} / \mathrm{m}^{3}\right)$ & Rock types \\
\hline DK68 $+285-305$ & V & Very poor & 1225 & 2230 & Granite, monzontic granite, diorite-porphyrite \\
DK68 $+305-360$ & IV & Poor & 3830 & 2570 & Granite, diorite-porphyrite \\
DK68 +360-448 & III & Fair & 4570 & 2630 & Granite \\
\hline
\end{tabular}

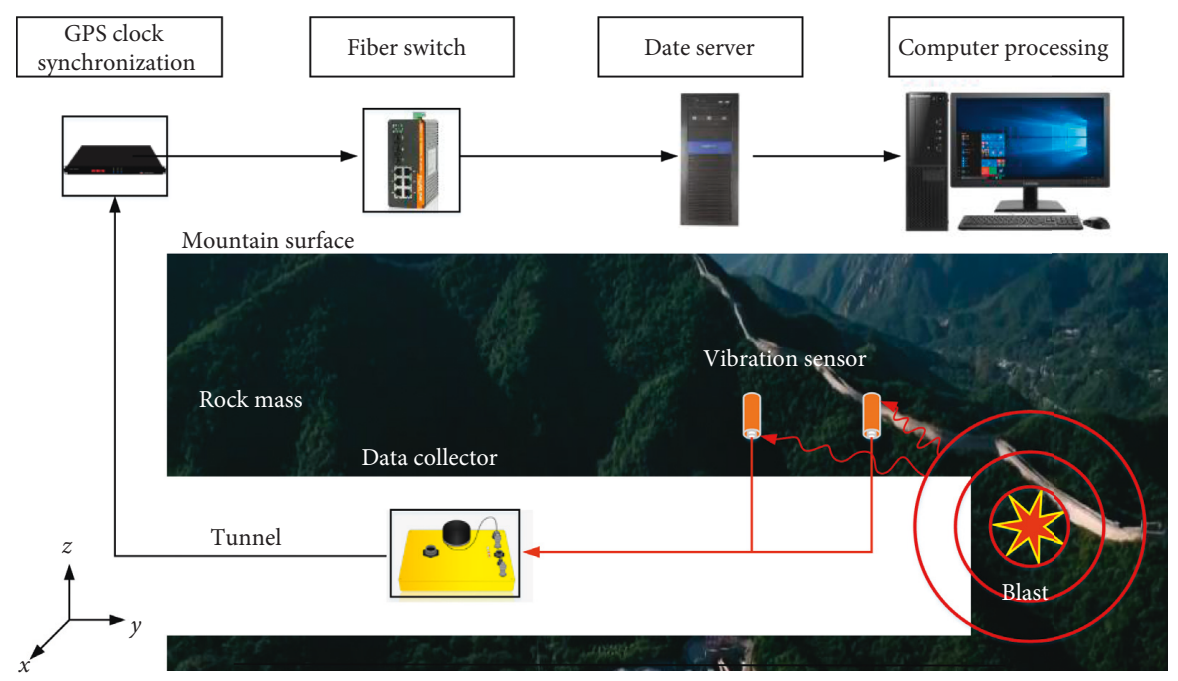

Figure 6: The diagram of microseismic monitoring system network.

Based on a large amount of measured data, linear regression analysis is used to obtain a linear relationship between $Y$ and $X$ data. The parameters $K$ and $\alpha$ can then be obtained. Figure 9 shows empirical fitting curves of PPV attenuation law along longitudinal, transverse, and vertical directions drawn based on the Sadovsky equation (equation (1)) using monitoring data. Attenuation coefficient $\alpha$ was obtained as a fixed value of $\alpha=2.3$ considering the geological conditions in the large-span tunnel. The fitting parameters of empirical equations along three directions are shown in Table 3.
The large-span tunnels were excavated below the Badaling Great Wall Scenic, and the overburden depth of the tunnels varied from $52 \mathrm{~m}$ to $85 \mathrm{~m}$. To ensure the safety of historic buildings and service infrastructures, the blasting vibration must be strictly controlled. Therefore, the precise blasting technology of electronic detonator was conducted. Compared with conventional blasting technology, the precise blasting technology can reduce the blasting vibration velocity from $5 \mathrm{~cm} / \mathrm{s}$ to $0.2 \mathrm{~cm} / \mathrm{s}$, which makes the fitting parameters $K$ relatively small compared to the published 


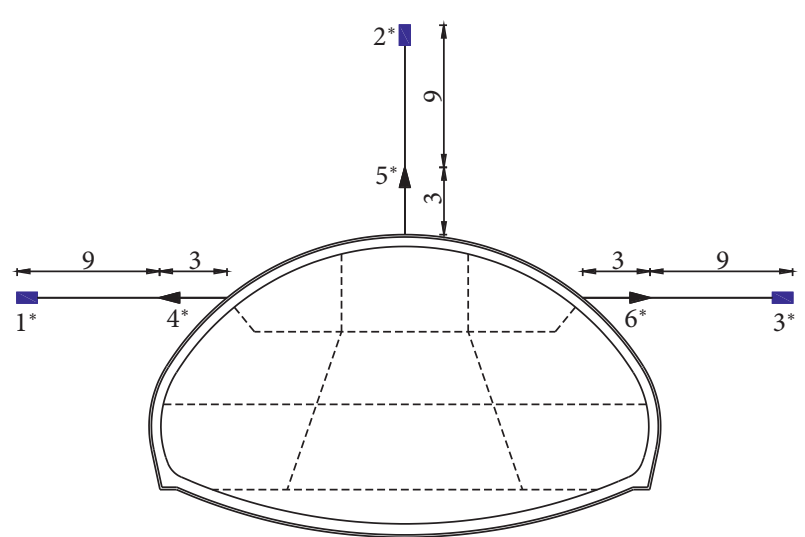

Internal measurement points with three-component sensor

\Internal measurement points with single-component sensor

FIgURE 7: Layout of measuring points inside the tunnel at DK68 + 290 (unit: m).

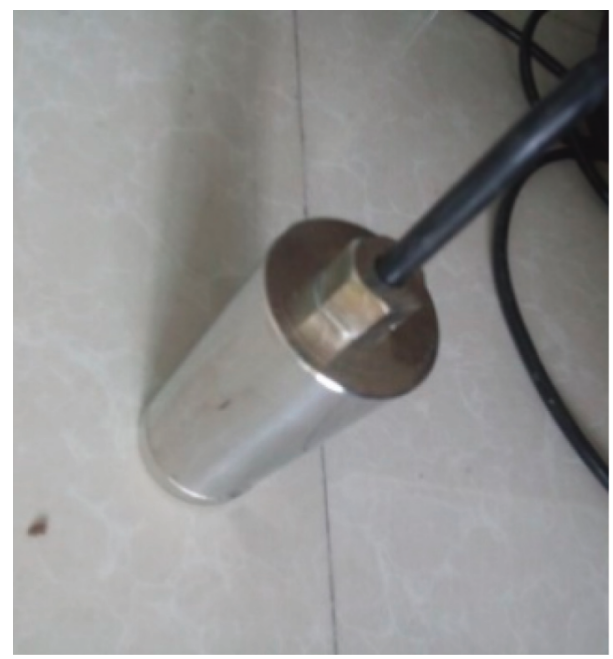

(a)

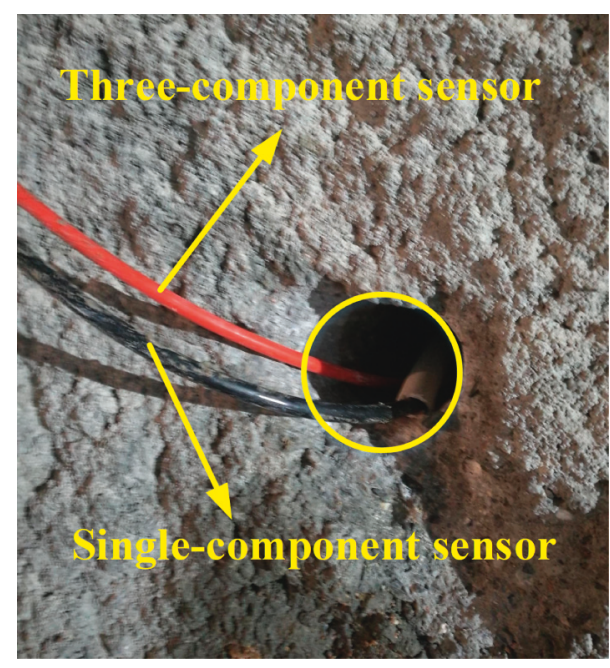

(b)

FIgURE 8: Installation of monitoring sensors inside the tunnel: (a) vibration sensor and (b) installing position. results [4-7]. Analysis of monitoring data (Table 3 and Figure 9) showed that PPV- $Z$ values at blasting vibration monitoring points were about 1.5-2 times higher than PPV$X$ and PPV-Y. It was concluded that vertical velocity had a major controlling effect on blasting vibration under current geotechnical conditions. Since the monitoring scheme with symmetry testing points inner the tunnel was carried out for blast vibration monitoring under the large-span tunnel construction, distance between the blasting point and monitoring sensors $R$ varied from 38 to $73 \mathrm{~m}$. Because the propagation paths of blasting wave are all in the rock, extrapolations outside this range can also be permitted using the fitted curves.

3.3. Distribution of Vibration Predominate Frequency. Previous studies have shown that vibration frequency plays a significant role in vibration-induced rock damages. The natural frequencies of concrete structures are generally below $10 \mathrm{~Hz}$; therefore, high-frequency vibration is beneficial to structural safety because of reduction in the probability of resonance [29]. Blast signal was processed using microseismic analysis software. The diagrams of waveform, time-frequency, and spectrum of a typical blast are shown in Figure 10. As can be seen in Figure 10, the duration time of a typical blasting is $0.7 \mathrm{~s}$. The frequency of a blast was in the range of 20 to $80 \mathrm{~Hz}$, and predominant frequency was about $60 \mathrm{~Hz}$.

Distribution of vibration predominate frequency of the 23 blasting signal sets is shown in Figure 11. As can be seen, frequency ranged from 55 to $120 \mathrm{~Hz}$, of which $70 \%$ of the obtained data were in the range of $90-110 \mathrm{~Hz}$. Hence it was concluded that, under the conditions of this experiment, blasts inside tunnel would not create resonance in concrete structure.

3.4. Analysis of Blasting Stress Based on PPV. Strain and dynamic stress can be determined from the value of PPV [30]. Dynamic stress $\sigma$ corresponding to the PPV of the material due to blasting was $[31,32]$

$$
\begin{aligned}
\sigma & =K_{n} \mathrm{PPV}, \\
K_{n} & =\rho V_{\mathrm{p}},
\end{aligned}
$$

where $K_{n}$ is the wave impedance of material $\left(\mathrm{kg} / \mathrm{m}^{2} \cdot \mathrm{s}\right), \rho$ is the density of material $\left(\mathrm{kg} / \mathrm{m}^{3}\right)$, and $V_{\mathrm{p}}$ is propagation velocity of $P$ wave $(\mathrm{m} / \mathrm{s})$ through the material.

3.4.1. Wave Impedance of Rock Mass and Shotcrete. P waves were focused on due to the first-arrival principle in the paper. The propagation velocity $V_{\mathrm{p}}$ of $P$ waves $(\mathrm{m} / \mathrm{s})$ in an elastic material is given by its stiffness, and the density of material is as follows $[33,34]$ :

$$
V_{\mathrm{p}}=\sqrt{\frac{E}{\rho}},
$$

where $E$ is elastic modulus $(\mathrm{GPa})$. 
TABLE 2: One set of monitoring data.

\begin{tabular}{|c|c|c|c|c|c|c|c|c|}
\hline Test ID (date) & $M_{\mathrm{w}}$ & Monitoring point & $R(\mathrm{~m})$ & $f(\mathrm{~Hz})$ & $\mathrm{PPV}-X(\mathrm{~mm} / \mathrm{s})$ & $\mathrm{PPV}-Y(\mathrm{~mm} / \mathrm{s})$ & $\mathrm{PPV}-Z(\mathrm{~mm} / \mathrm{s})$ & $Q(\mathrm{~kg})$ \\
\hline \multirow{12}{*}{$170671(2017 / 6 / 3)$} & \multirow{12}{*}{-0.05} & $1^{*}-\mathrm{I}$ & 44.2 & \multirow{12}{*}{101} & 0.24 & 0.38 & 0.45 & \multirow{12}{*}{120} \\
\hline & & $4^{*}-\mathrm{I}$ & 41 & & - & - & 0.82 & \\
\hline & & $2^{*}-\mathrm{I}$ & 51.2 & & 0.24 & 0.62 & 0.56 & \\
\hline & & $5^{*}-\mathrm{I}$ & 44.5 & & - & - & 0.68 & \\
\hline & & $3^{*}-\mathrm{I}$ & 37.6 & & 0.53 & 0.56 & 0.8 & \\
\hline & & $6^{*}-\mathrm{I}$ & 38.2 & & - & - & 0.91 & \\
\hline & & $1^{*}$-II & 73.1 & & 0.10 & 0.22 & 0.23 & \\
\hline & & $4^{*}$-II & 40 & & - & - & 0.85 & \\
\hline & & $2^{*}-\mathrm{II}$ & 73.3 & & 0.11 & 0.27 & 0.26 & \\
\hline & & $5^{*}-\mathrm{II}$ & 68.3 & & - & - & 0.32 & \\
\hline & & $3^{*}-\mathrm{II}$ & 64.8 & & 0.14 & 0.13 & 0.28 & \\
\hline & & $6^{*}-\mathrm{II}$ & 64.1 & & - & - & 0.36 & \\
\hline
\end{tabular}

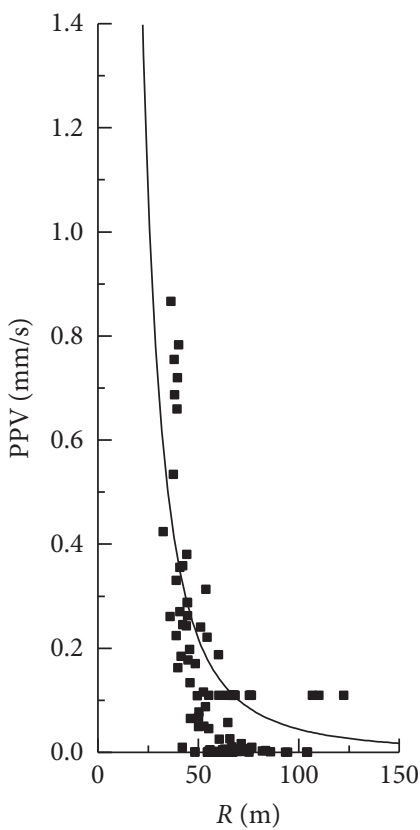

- $\quad$ PPV $-X$

Fitting curve

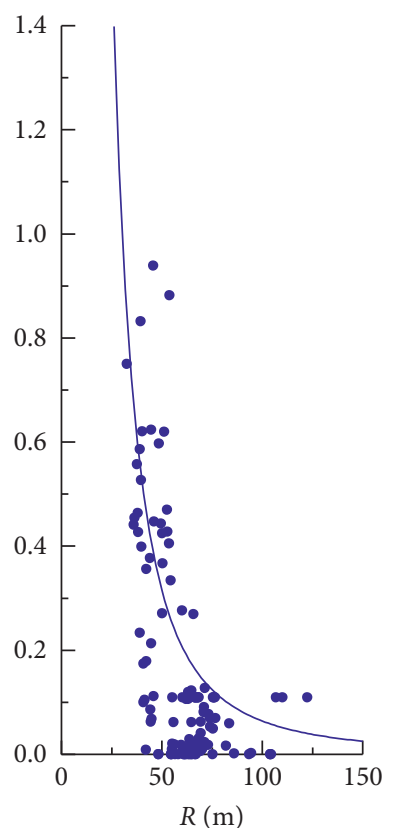

- $\mathrm{PPV}-\mathrm{Y}$

Fitting curve

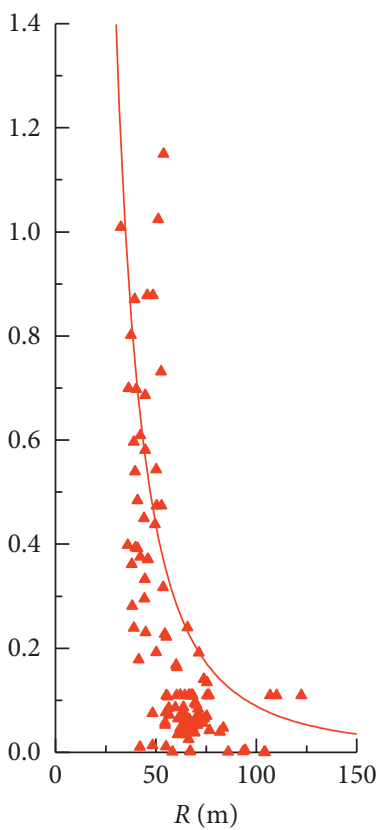

- PPV $-Z$

Fitting curve

FIgURE 9: Fitting curves between PPV and $R$ with $Q=120 \mathrm{~kg}$.

TABLE 3: Fitting results of PPV-X, PPV- $Y$, and PPV-Z (unit: $\mathrm{mm} / \mathrm{s}$ ).

\begin{tabular}{lccc}
\hline & PPV $-X$ & $P P V-Y$ & $P P V-Z$ \\
\hline $\begin{array}{l}\text { Fitting } \\
\text { equations }\end{array}$ & $V=45(\sqrt[3]{\mathrm{Q}} / R)^{2.3}$ & $V=65(\sqrt[3]{\mathrm{Q}} / R)^{2.3}$ & $V=90(\sqrt[3]{\mathrm{Q}} / R)^{2.3}$ \\
\hline
\end{tabular}

In this work, it was assumed that the development of elastic modulus $E$ for hardening shotcrete followed an empirical function derived from a large number of tests $[32,35]$. The elastic modulus $E(t)$ of C20 shotcrete at different ages $t$ (days) is given as follows:

$$
E(t)=36.72\left(1-e^{-0.4 t^{0.34}}\right) \text {. }
$$

By substituting equations (4) and (5) into equation (3), the equation of wave impedance of shotcrete was obtained as follows:

$$
\rho_{\mathrm{S}} V_{\mathrm{PS}}=\sqrt{\frac{E(t)}{\rho_{\mathrm{S}}}}
$$



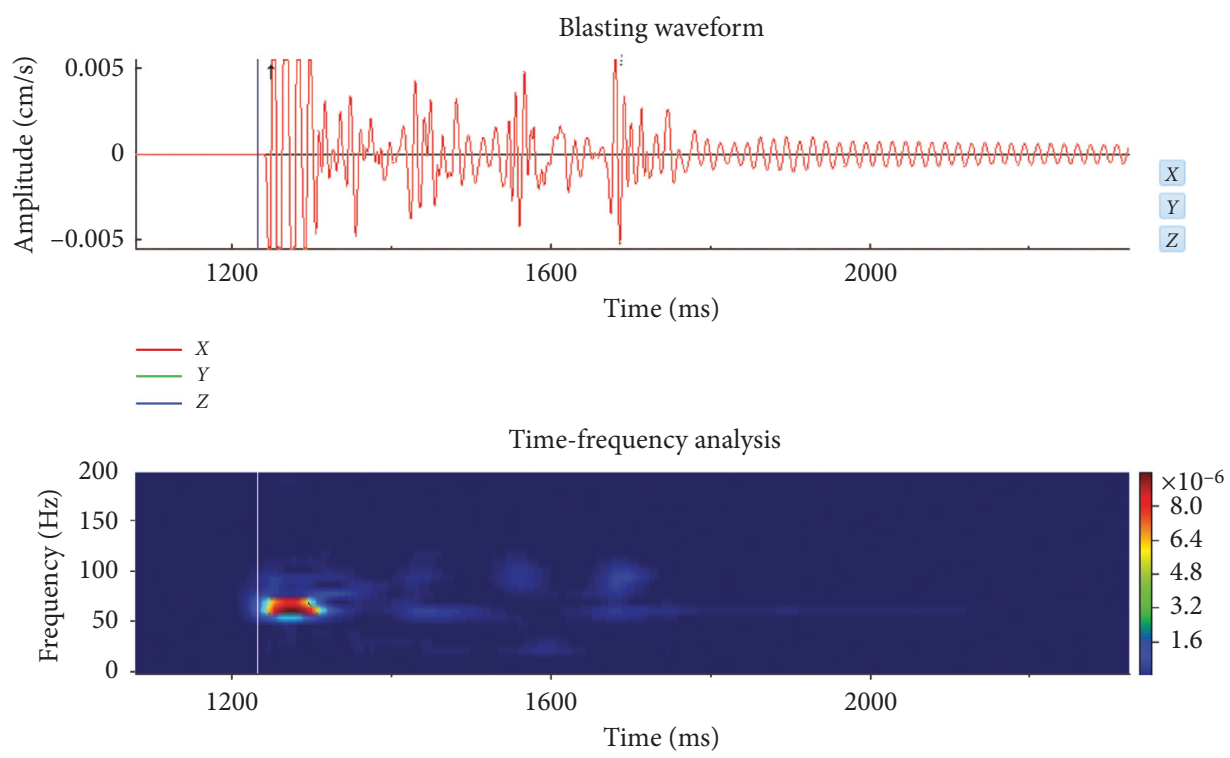

(a)

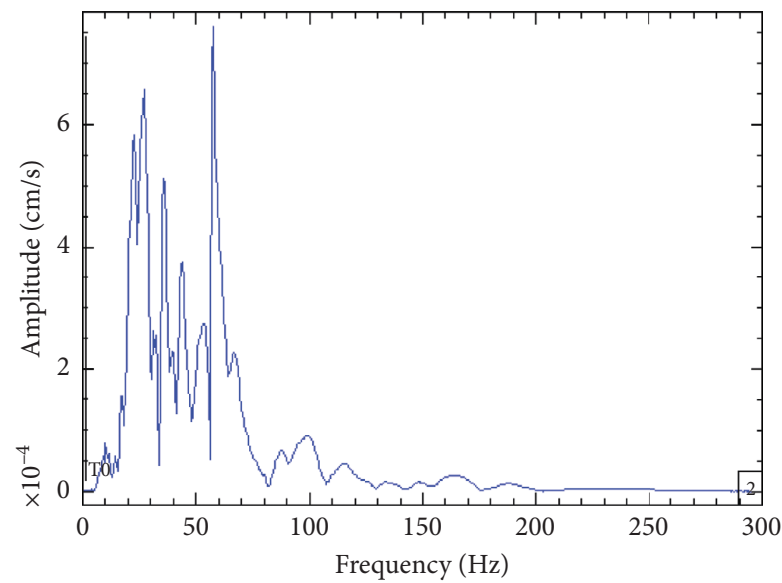

(b)

FIGURE 10: Blasting signal: (a) waveform and time-frequency analysis and (b) spectrum analysis.

where $\rho_{\mathrm{S}}$ is shotcrete density which was assumed to be $2300 \mathrm{~kg} \cdot \mathrm{m}^{-3}$ and $V_{\text {PS }}$ is propagation velocity of $P$ wave $(\mathrm{m} / \mathrm{s})$ through shotcrete.

Based on rock mass properties of large-span tunnel summarized in Table 1, the wave impedances of different rock masses could be obtained by equation (3).

3.4.2. Reflection and Transmission of Blasting Wave. Due to different material properties, vibration velocities induced by dynamic loads in shotcrete are different from those in rock masses [32]. Based on the wave theory of reflection and transmission, a wave that is incident $\left(v_{\mathrm{I}}\right)$ on a boundary generally creates reflected $\left(v_{\mathrm{R}}\right)$ and transmitted $\left(v_{\mathrm{T}}\right)$ waves when passing from medium 1 to medium 2 . The velocities and stresses of both reflected and transmitted waves could be expressed as $[36,37]$

$$
\begin{aligned}
& \left\{\begin{array}{l}
v_{\mathrm{R}}=-F v_{\mathrm{I}}, \\
\sigma_{\mathrm{R}}=F \sigma_{\mathrm{I}},
\end{array}\right. \\
& \left\{\begin{array}{l}
v_{\mathrm{T}}=n T v_{\mathrm{I}}, \\
\sigma_{\mathrm{T}}=T \sigma_{\mathrm{I}},
\end{array}\right.
\end{aligned}
$$

$$
\left\{\begin{array}{l}
F=\frac{1-n}{1+n}, \\
T=\frac{2}{1+n}, \\
n=\frac{\left(\rho V_{\mathrm{p}}\right)_{1}}{\left(\rho V_{\mathrm{p}}\right)_{2}},
\end{array}\right.
$$




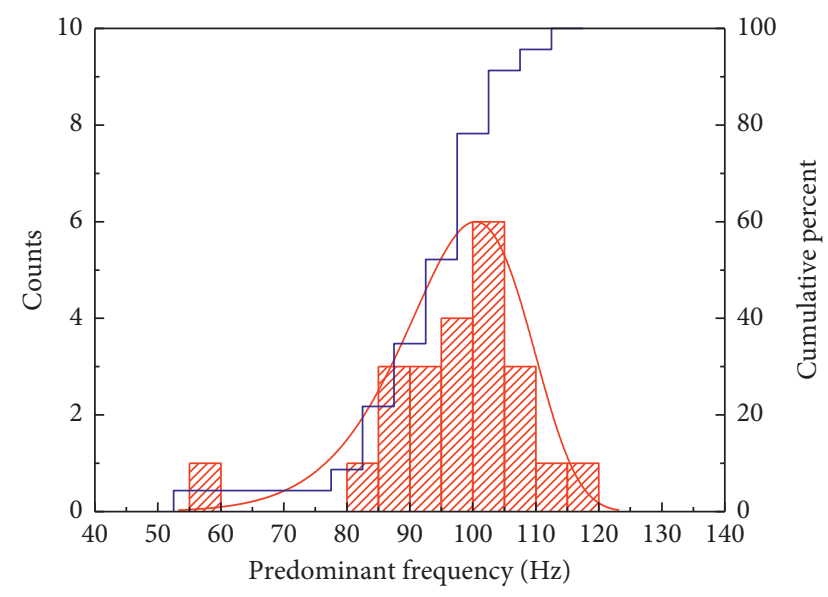

FIGURE 11: Distribution of vibration predominate frequency.

where $\sigma_{\mathrm{I}}$ is the compressive stress of incident wave $v_{\mathrm{I}}$ with $\sigma_{\mathrm{I}}=\left(\rho V_{\mathrm{p}}\right)_{1} v_{\mathrm{I}},\left(\rho V_{\mathrm{p}}\right)_{1}$, and $\left(\rho V_{\mathrm{p}}\right)_{2}$ are wave impedances in media 1 and 2, respectively, $n$ is wave impedance coefficient ratio of medium 1 to medium $2, F$ is the reflection coefficient, and $T$ is the transmission coefficient.

During tunnel excavation, explosive compressive stress wave $\left(v_{\mathrm{I}}\right)$ propagating in rock mass was divided into reflected $\left(v_{\mathrm{R}}\right)$ and transmission $\left(v_{\mathrm{T}}\right)$ stress waves in shotcrete when encountering rock-shotcrete interface as shown in Figure 12-(1). Based on the wave impedances of rock mass $\left(K_{\mathrm{R}}\right)$ and shotcrete $\left(K_{\mathrm{S}}\right)$ obtained in Section 3.4.1, the velocities and stresses of $v_{\mathrm{T}}$ and $v_{\mathrm{R}}$ were given as

$$
\begin{aligned}
& \left\{\begin{array}{l}
v_{\mathrm{R}}=-F_{1} v_{\mathrm{I}}, \\
\sigma_{\mathrm{R}}=F_{1} \sigma_{\mathrm{I}},
\end{array}\right. \\
& \left\{\begin{array}{l}
v_{\mathrm{T}}=n_{1} T_{1} v_{\mathrm{I}}, \\
\sigma_{\mathrm{T}}=T_{1} \sigma_{\mathrm{I}},
\end{array}\right.
\end{aligned}
$$

where $n_{1}, F_{1}$, and $T_{1}$ are wave impedance coefficient ratio and reflection and transmission coefficients from rock mass to shotcrete, respectively.

Stress wave theory states that blasting stress wave $\left(v_{\mathrm{T}}\right)$ only turns into reflection wave $\left(v_{\mathrm{TR}}\right)$ when passing from the free surface of shotcrete to air because there is no transmission wave with the wave impedance of air $\left(K_{\mathrm{A}}\right)$ being close to zero as shown in Figure 12-(2). The velocities and stresses of $v_{\mathrm{TR}}$ and $v_{\mathrm{TT}}$ can be calculated as follows:

$$
\begin{aligned}
& \left\{\begin{array}{l}
v_{\mathrm{TR}}=-F_{2} n_{1} T_{1} v_{\mathrm{I}}=n_{1} T_{1} v_{\mathrm{I}}, \\
\sigma_{\mathrm{TR}}=F_{2} T_{1} \sigma_{\mathrm{I}}=-T_{1} \sigma_{\mathrm{I}},
\end{array}\right. \\
& \left\{\begin{array}{l}
v_{\mathrm{TT}}=n_{2} T_{2} n_{1} T_{1} v_{\mathrm{I}}=0, \\
\sigma_{\mathrm{TT}}=T_{2} T_{1} \sigma_{\mathrm{I}}=0,
\end{array}\right.
\end{aligned}
$$

where $n_{2}, F_{2}$, and $T_{2}$ are wave impedance coefficient ratio and reflection and transmission coefficients from shotcrete to air, respectively, and the values of $F_{2}$ and $T_{2}$ are -1 and 0 , respectively.

Furthermore, $v_{\mathrm{TR}}$ was continuously reflected and transmitted when encountering with rock-shotcrete interface as shown in Figure 12-(3). The velocities and stresses of $v_{\mathrm{TRR}}$ and $v_{\mathrm{TRT}}$ were calculated as follows:

$$
\begin{aligned}
& \left\{\begin{array}{l}
v_{\mathrm{TRT}}=-F_{3} n_{1} T_{1} v_{\mathrm{I}}, \\
\sigma_{\mathrm{TRT}}=-F_{3} T_{1} \sigma_{\mathrm{I}},
\end{array}\right. \\
& \left\{\begin{array}{l}
v_{\mathrm{TRT}}=n_{3} T_{3} n_{1} T_{1} v_{\mathrm{I}}, \\
\sigma_{\mathrm{TRT}}=-T_{3} T_{1} \sigma_{\mathrm{I}},
\end{array}\right.
\end{aligned}
$$

where $n_{3}, F_{3}$, and $T_{3}$ are wave impedance coefficient ratio and reflection and transmission coefficients from shotcrete to rock mass, respectively.

Under the existing blast conditions, PPV- $Z$ was much higher than horizontal velocities. Therefore, according to the results obtained from empirical equations for PPV mentioned above, $v_{\mathrm{I}}$ as the maximum vibration wave had to be equal to PPV-Z. As shown in Figure 12, after three reflection and transmission cycles of blast stress wave, it was found that only $\sigma_{\mathrm{TR}}$ and $\sigma_{\mathrm{TRT}}$ were tensile stresses, of which $\sigma_{\mathrm{TRT}}$ was imposed on shotcrete-rock interface and $\sigma_{\mathrm{TR}}$ was imposed on shotcrete. This could be expressed as

$$
\begin{aligned}
\sigma_{\mathrm{TR}} & =-T_{1} \sigma_{\mathrm{I}}=-\frac{2}{1+n_{1}} \sigma_{\mathrm{I}}, \\
\sigma_{\mathrm{TRT}} & =-n_{1} T_{1}^{2} \sigma_{\mathrm{I}}=D_{\mathrm{TRT}} \sigma_{\mathrm{I}}, \\
D_{\mathrm{TRT}} & =-\frac{4 n_{1}}{\left(1+n_{1}\right)^{2}},
\end{aligned}
$$

where $D_{\text {TRT }}$ is the coefficient of tensile stress imposed on the interface.

\section{Determination of Safety Distance of Shotcrete under Bond Failure Criterion}

The most fundamental characteristic of shotcrete is its ability to adhere to rock surface which depends on the adhesion strength between shotcrete and rock [32]. It has been found that the failure of shotcrete support is mainly due to the separation of shotcrete and rock at the rock-shotcrete interface [38]. Therefore, to determine the security of shotcrete, the bond strength of shotcrete-rock interface should be compared with the tensile stress of interface caused by blasting.

4.1. Bond Strength of Shotcrete-Rock Interface. The bond strength of shotcrete-rock interfaces with C20 shotcrete and rock masses with different classes within 28 days was obtained as follows $[32,36]$ :

$$
\sigma_{\mathrm{b}}=2.345 \sigma_{24 \mathrm{hb}} e^{-0.858 t^{-0.97}},
$$

where $t$ is shotcrete age (day) and $\sigma_{24 \mathrm{hb}}$ is average evaluation bond strength within 24 hours $(\mathrm{MPa})$, and its value should not be lower than $0.8,0.5,0.42$, and $0.31 \mathrm{MPa}$ for rock mass classes of II, III, IV, and V, respectively [39].

As shown in Figure 13, the mechanical parameters of shotcrete were closely related to its age $1-3,3-7$, and 7-28 days are typical curing ages of shotcrete. And the bond strength is in the rapid growth stage within 3 days. 


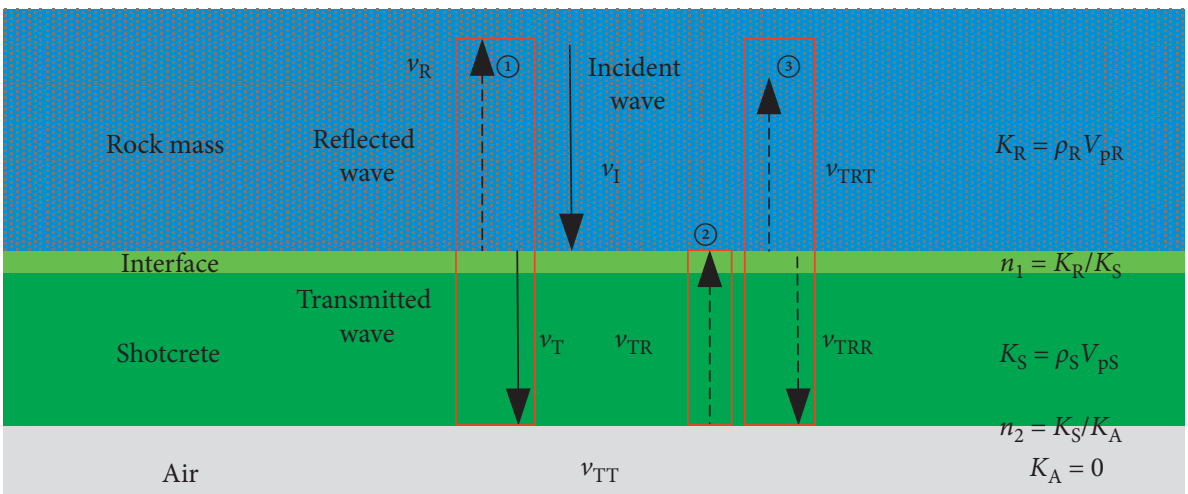

FIGURE 12: Three times of reflections and transmissions of blast stress wave.

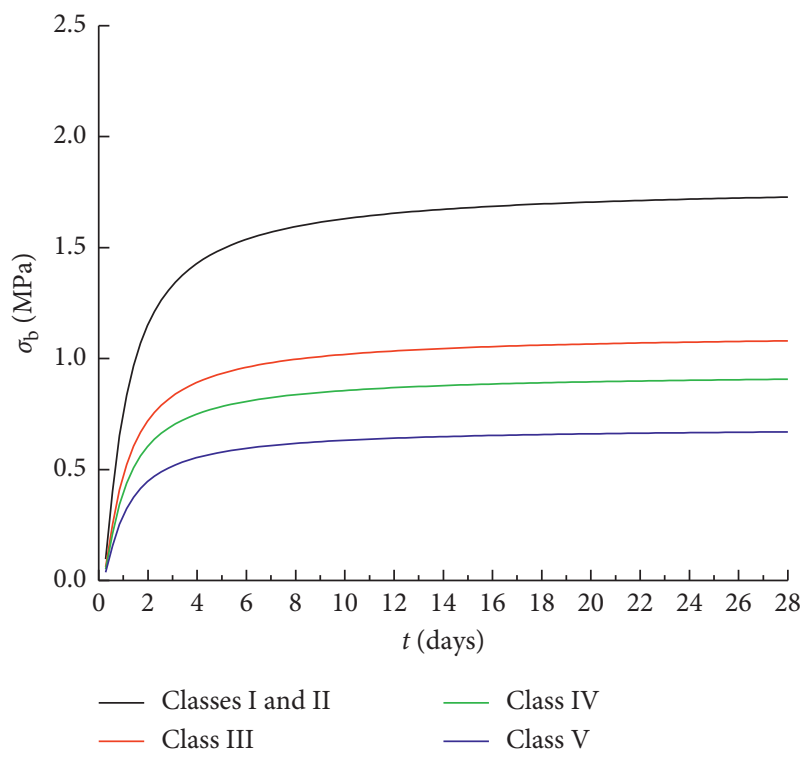

Figure 13: Bond strength of interface between shotcrete and different rock mass classes within 28 days.

\subsection{Calculation of Safety Distance of Shotcrete.} Shotcrete-rock interface may suffer from bond failure when maximum tensile stress caused by blasting exceeds the bond strength of the interface which can be expressed as [40]

$$
\sigma_{\mathrm{p}}>\sigma_{\mathrm{b}}
$$

where $\sigma_{\mathrm{p}}$ is maximum tensile stress with $\sigma_{\mathrm{p}}=\sigma_{\mathrm{TRT}}$ and $\sigma_{\mathrm{b}}$ is the bond strength of shotcrete-rock interface.

To ensure the security of shotcrete, the tensile stress of rock-shotcrete interface caused by blasting should be lower than its bond strength. Therefore, the safety distance threshold from blasting work face beyond which the shotcrete is able to withstand blasting vibration has to be derived. Substituting the formulas of $\sigma_{\mathrm{p}}$ and $\sigma_{\mathrm{b}}$ obtained in Sections $3.2,3.4$, and 4.1 into equation (15), minimum safety distance equation can be expressed as

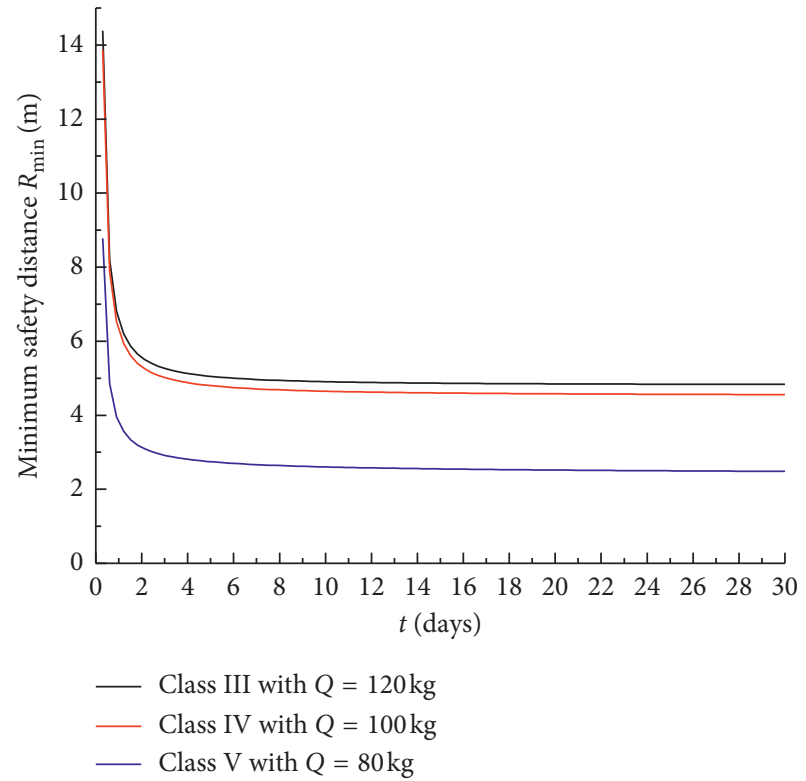

FIGURE 14: Relationship between minimum safety distances and age of concrete for different rock mass class conditions.

$$
\begin{aligned}
R_{\min } & =S_{R}\left[\exp \left(-0.858 t^{-0.97}\right)\right]^{-(1 / 2.3)}, \\
S_{R} & =Q^{1 / 3}\left[24.8\left(\frac{\sigma_{24 \mathrm{hb}}}{K_{n} D_{\mathrm{TRT}}}\right)\right]^{-(1 / 2.3)},
\end{aligned}
$$

where $R_{\min }$ is minimum safety distance and $S_{R}$ is a parameter related to blasting charge and geotechnical condition.

Figure 14 shows that the safety distance of shotcrete is decreased with the increase of age. Also, blasting charge is decreased with the weakening of rock mass to validly reduce the blast vibration. Blasting charge of classes III, IV, and V rock mass conditions were 120,100 , and $80 \mathrm{~kg}$, respectively. Hence, as shown in Figure 14, safety distance is decreased with rock mass condition changing from III to $\mathrm{V}$.

Because the propagation paths of blasting wave are all in the rock, the PPV can also be predicated using the fitted curves when the distance $R$ is outside this range, though the 
TABLE 4: Sensitivity of different parameters affecting safety distances.

\begin{tabular}{lcc}
\hline Parameters & Range of parameters & Sensitivity of parameters \\
\hline Rock mass class & III, IV, V & 0.96 \\
Blasting charge $Q(\mathrm{~kg})$ & $140,120,100,80,60$ & 0.43 \\
Age of shotcrete $t(\mathrm{~h})$ & $0.5,1,1.5,2,2.5,3,3.5,4,4.5,5,5.5,6$ & 0.50 \\
\hline
\end{tabular}

TABLE 5: Safety standard of blasting vibration for mass fresh concrete suggested in Chinese Safety Standard for Blasting Vibration (unit: $\mathrm{cm} / \mathrm{s}$ ).

\begin{tabular}{ccccc}
\hline \multicolumn{2}{c}{ Fresh concrete of $\mathrm{C} 20$} & \multicolumn{3}{c}{ Safety standard of blasting vibration velocity (cm/s) } \\
Predominate frequency $f(\mathrm{~Hz})$ & $\leq 10$ & $10-50$ & $>50$ \\
\hline \multirow{3}{*}{ Concrete age } & $0 \sim 3 \mathrm{~d}$ & $1.5 \sim 2$ & $2 \sim 2.5$ & $2.5 \sim 3$ \\
& $3 \sim 7 \mathrm{~d}$ & $3 \sim 4$ & $4 \sim 5$ & $5 \sim 7$ \\
& $7 \sim 28 \mathrm{~d}$ & $7 \sim 8$ & $8 \sim 10$ & $10 \sim 12$ \\
\hline
\end{tabular}

TABLE 6: Minimum safety distances of shotcretes subjected to blasting vibration using two different criteria (unit: m).

\begin{tabular}{|c|c|c|c|c|c|c|c|}
\hline \multirow{2}{*}{ Rock mass class } & \multirow{2}{*}{$Q(\mathrm{~kg})$} & \multicolumn{3}{|c|}{ Bond failure criterion } & \multicolumn{3}{|c|}{ Chinese safety standard } \\
\hline & & $0.5-3 \mathrm{~d}$ & $3-7 d$ & $7-28 \mathrm{~d}$ & $0-3 \mathrm{~d}$ & $3-7 d$ & $7-28 \mathrm{~d}$ \\
\hline III & 120 & $5.27-9.24$ & $4.83-5.27$ & $4.83-4.97$ & $7.95-8.61$ & $5.50-6.37$ & $4.35-4.71$ \\
\hline IV & 100 & $5.02-8.89$ & $4.56-5.02$ & $4.56-4.71$ & $7.48-8.10$ & $5.18-5.99$ & $4.10-4.43$ \\
\hline V & 80 & $2.92-5.52$ & $2.49-2.92$ & $2.49-2.67$ & $6.95-7.52$ & $4.81-5.56$ & $3.80-4.12$ \\
\hline
\end{tabular}

distances between the blasting points and monitoring sensors $R$ are within $38-73 \mathrm{~m}$. The sensitivity analysis was conducted to quantify the effects of several inputs parameters which were blasting charge, rock mass class, and age of shotcrete. According to the sensitivity analysis results in Table 4, rock mass class has the greatest influence on safety distance, followed by age of shotcrete and blasting charge.

In Chinese Safety Standard for Blasting Vibration (GB6722-2014), some standard values have been provided for safe PPV of mass fresh concrete taking into account vibration frequency, as summarized in Table 5 [18]. Based on the empirical equation obtained for PPV $-Z$ and blast predominant frequency in Sections 3.2 and 3.3, minimum safety distance was obtained to satisfy PPV safety standard.

Minimum safety distance thresholds for shotcrete were evaluated using bond failure criterion and Chinese Safety Standard for Blasting Vibration, and the obtained results are summarized as shown in Table 6. By comparing minimum safety distances determined based on two different criteria, namely, bond failure criterion and Chinese Safety Standard Blasting Vibration, it was observed that both results complied well under classes III and IV rock mass conditions. However, under class $\mathrm{V}$ rock mass condition, minimum safety distance using bond failure criterion was much lower. The reason is that rock mass properties under class $\mathrm{V}$ condition were significantly different from those under class III and IV conditions, as can be seen in Table 1. The differences in properties were taken into sufficient consideration when using bond failure criterion, but this was not the case for Chinese Safety Standard for Blasting Vibration. Therefore, minimum safety distance using bond failure criterion was found to be more precise and practical under complex conditions.
In this project, the shotcrete of steel fiber concrete with two layers was adopted as the support system. The distance that the excavation of the upper bench lags behind the lower bench was $30 \mathrm{~m}$. The shotcrete thicknesses of primary and secondary layers are $150 \mathrm{~mm}$ and $200 \mathrm{~mm}$, respectively. Since primary shotcrete was too close to blasting face, blasting vibration could affect primary shotcrete structure and cause irreversible damage. Therefore, here the safety of secondary shotcrete was considered. Based on excavation and support processes, the distance between secondary shotcrete and blasting point was above $6 \mathrm{~m}$ (2 excavation cycles), and the blast was carried out 3 days after shotcrete was performed. Hence, according to minimum safety distances summarized in Table 6 , the safety of secondary shotcrete was ensured and shotcrete falling off was prevented under the current blast construction.

4.3. Recommendations for the Security of Shotcrete. In the construction of large-span tunnels, blasting vibration may cause undesired damages to shotcrete. Based on the above analyses, safety distance can be determined to ensure the security of shotcrete according to the monitoring results of blasting vibration. However, due to the tight time limits of large construction projects, blasting is often performed before bond strength of shotcrete is reached and with the distance between blast work face and shotcrete below safety distance. Despite these problems and difficulties, some effective measurements can be taken to ensure the safety of shotcrete construction, as follows:

(1) Steel fiber shotcretes have high early strength which can improve bond the strength of shotcretes to withstand blast loads in tunnel excavations in short 
time periods [1, 2, 41-43]. According to equation (16), adopting steel fiber concrete can improve the bond characteristic of the interface $\left(\sigma_{24 \mathrm{hb}}\right)$ and thus increases the safety distance of shotcrete.

(2) Operation sequences in tunnel excavation can be ordered to reduce blast charge and therefore significantly controls blast vibration [21, 44]. A certain distance should be kept between upper and lower benches to keep the shotcrete from being repeatedly disturbed by blasting in a short time. According to equation (16), when blasting charge was decreased, safety distance of shotcrete was also decreased.

(3) Performing multiple shotcrete layers is an effective method to decrease blasting damage $[35,43]$. The initial shotcrete with low layer thickness was performed to seal the rock mass to facilitate the installation of metal meshes and bolts. The subsequent concrete layer with higher thickness was sprayed often with 1-3 days or 1-2 excavation cycle delay to consolidate the compound system of rock mass and support. Because of the increased distance between blast point and shotcrete, the blast vibration imposed on subsequent shotcrete was dramatically decreased.

\section{Conclusions}

In this work, blasting vibration monitoring was carried out using microseismic monitoring technique during the blast excavation of the large-span tunnel of Badaling Great Wall Station. Blasting vibration parameters including peak particle velocity (PPV) and blast predominate frequency $(f)$ were recorded by using the microseismic monitoring system installed inside the tunnel. Empirical equations of PPV were obtained by regression analysis based on monitoring data. The blast vibration tensile stress of shotcrete-rock interface caused by blasting and bond characteristics of interface was also analyzed. The safety distance between blasting and shotcrete was proposed to ensure the security of shotcrete. The main conclusions were drawn as follows:

(1) The equations to predict blast vibration characteristics along longitudinal, transverse, and vertical directions were derived using the Sadovsky empirical equation. Vertical peak particle velocity (PPV-Z) was approximately 1.5-2 times higher than that along radial and tangential directions (PPV-X, PPV-Y).

(2) Due to the different wave impedances of shotcrete and rock masses, the tensile stress $\sigma_{\mathrm{TRT}}$ imposed on the shotcrete-rock interface was calculated after reflections and transmissions of blast stress wave caused by blasting.

(3) Based on the bond failure criterion of shotcreterock interface, the calculation equation of minimum safety distance of shotcrete subjected to blast vibration was obtained which could be applied to determine blast charge and shotcrete arrangements. It was witnessed that the minimum safety distance of shotcrete was decreased with the increase of age which was more significant in the first three days.

(4) In this project, the distance between secondary shotcrete and blasting point was above $6 \mathrm{~m}$ and blasting was carried out 3 days after shotcrete was performed. Therefore, the vibration safety of secondary shotcrete was ensured and shotcrete falling off the rock was prevented.

\section{Notations}

$V_{\mathrm{p}}: \quad P$ wave velocity of rock mass $(\mathrm{km} / \mathrm{s})$

PPV: Peak particle velocity of vibration $(\mathrm{mm} / \mathrm{s})$

$Q: \quad$ Blasting charge $(\mathrm{kg})$

$R$ : $\quad$ The distance from the blasting point to the measuring point $(\mathrm{m})$

$f: \quad$ Predominate frequency $(\mathrm{Hz})$

$M_{\mathrm{w}}$ : Moment magnitude

$\rho: \quad$ The density of material $\left(\mathrm{kg} / \mathrm{m}^{3}\right)$

$\rho_{\mathrm{S}}: \quad$ The density of shotcrete $\left(\mathrm{kg} / \mathrm{m}^{3}\right)$

E: $\quad$ Elastic modulus $(\mathrm{GPa})$

$v_{\mathrm{I}}: \quad$ Incident wave $(\mathrm{mm} / \mathrm{s})$

$\sigma_{\mathrm{I}}: \quad$ Compressive stress of incident wave (MPa)

$n$ : Wave impedance coefficient ratio

F: $\quad$ Reflection coefficient

T: $\quad$ Transmission coefficient

$\sigma_{\mathrm{b}}$ : Bond strength of shotcrete-rock interfaces (MPa)

$\sigma_{24 \mathrm{hb}}$ : Average evaluation bond strength within 24 hours $(\mathrm{MPa})$

$\sigma_{\mathrm{p}}: \quad$ Maximum tensile stress (MPa)

$D_{\mathrm{TRT}}$ : The coefficient of tensile stress imposed on the interface

$R_{\min }$ : Minimum safety distance (m)

SR: $\quad$ Parameter related to blasting charge and geotechnical condition.

\section{Data Availability}

The data used to support the findings of this study are included within the article.

\section{Conflicts of Interest}

The authors declare no conflicts of interest.

\section{Acknowledgments}

This work was supported by the Fundamental Research Funds for Chinese National Natural Science Foundation under Grant 51678035, National Key Research and Development Programs of China under Grant 2017YFC0805401, the Fundamental Research Funds for the Central Universities under Grant 2017JBZ104, and China Railway Corporation Research and Development Program of Science and Technology under Grant 2014004-C. 


\section{References}

[1] T. Franzén, "Shotcrete for rock support: a summary report on the state of the art in 15 countries," Tunnelling and Underground Space Technology, vol. 8, no. 4, pp. 441-470, 1993.

[2] P. Li, F. Wang, and Q. Fang, "Undrained analysis of ground reaction curves for deep tunnels in saturated ground considering the effect of ground reinforcement," Tunnelling and Underground Space Technology, vol. 71, no. 1, pp. 579-590, 2018.

[3] V. Ghiasi and H. Omar, "Analysis of shotcrete lining of underground tunnels," Pertanika Journal of Science \& Technology, vol. 19, no. 2, pp. 249-257, 2011.

[4] J. H. Yang, W. B. Lu, Z. G. Zhao, P. Yan, and M. Chen, "Safety distance for secondary shotcrete subjected to blasting vibration in Jinping-II deep-buried tunnels," Tunnelling and Underground Space Technology, vol. 43, no. 7, pp. 123-132, 2014.

[5] L. Ahmed and A. Ansell, "Laboratory investigation of stress waves in young shotcrete on rock," Magazine of Concrete Research, vol. 64, no. 10, pp. 899-908, 2012.

[6] A. Ansell, "In situ testing of young shotcrete subjected to vibrations from blasting," Tunnelling and Underground Space Technology, vol. 19, no. 6, pp. 587-596, 2004.

[7] L. Ahmed and A. Ansell, "Vibration vulnerability of shotcrete on tunnel walls during construction blasting," Tunnelling and Underground Space Technology, vol. 42, no. 5, pp. 105-111, 2014.

[8] Z. G. Zhao, J. H. Yang, W. B. Lu, P. Yan, and M. Chen, "Selection of sprayed time for permanent shotcrete based on evaluation of blasting vibration impact in deep-buried tunnels," Journal of Vibration and Shock, vol. 34, no. 7, pp. 8-14, 2015.

[9] J.-H. Shin, H.-G. Moon, and S.-E. Chae, "Effect of blast-induced vibration on existing tunnels in soft rocks," Tunnelling and Underground Space Technology, vol. 26, no. 1, pp. 51-61, 2011.

[10] N. Jiang and C. Zhou, "Blasting vibration safety criterion for a tunnel liner structure," Tunnelling and Underground Space Technology, vol. 32, no. 6, pp. 52-57, 2012.

[11] G. R. Tripathy, R. R. Shirke, and M. D. Kudale, "Safety of engineered structures against blast vibrations: a case study," Journal of Rock Mechanics and Geotechnical Engineering, vol. 8, no. 2, pp. 248-255, 2016.

[12] S. Arora and K. Dey, "Estimation of near-field peak particle velocity-a mathematical model," Journal of Geology \& Mining Research, vol. 2, no. 4, pp. 68-73, 2010.

[13] R. N. Gupta, P. Pal Roy, and B. Singh, "Prediction of peak particle velocity and peak air pressure generated by buried explosion," International Journal of Mining and Geological Engineering, vol. 6, no. 1, pp. 15-26, 1988.

[14] C. Zhang, L. Cheng, J. Qiu, H. Ji, and J. Ji, "Structural damage detections based on a general vibration model identification approach," Mechanical Systems and Signal Processing, vol. 123, pp. 316-332, 2019.

[15] Q. Qiu and D. Lau, "Measurement of structural vibration by using optic-electronic sensor," Measurement, vol. 117, no. 3, pp. 435-443, 2018.

[16] N. Z. Meymian, N. Clark, J. Subramanian et al., "Quantification of windage and vibrational losses in flexure springs of a one kW two-stroke free piston linear engine alternator," in Proceedings of the 2019 SAE Technical Paper Series, Detroit, MI, USA, April 2019.
[17] M. A. Sadovskii, N. V. Mel'Nikov, and G. P. Demidyuk, "The main trends in the development of blasting techniques in mining," Soviet Mining Science, vol. 9, no. 3, pp. 257-264, 1973.

[18] GB6722-2014, Safety Regulations for Blasting, State Standardization Publishing House, Beijing, China, 2014.

[19] A. Bajrić and J. Høgsberg, "Identification of damping and complex modes in structural vibrations," Journal of Sound and Vibration, vol. 431, pp. 367-389, 2018.

[20] Y. Zeng, H. Li, X. Xia, B. Liu, H. Zuo, and J. Jiang, "Blastinduced rock damage control in Fangchenggang nuclear power station, China," Journal of Rock Mechanics and Geotechnical Engineering, vol. 10, no. 5, pp. 914-923, 2018.

[21] L. Xie, W. Lu, J. Gu, and G. Wang, "Excavation method of reducing blasting vibration in complicated geological conditions," Shock and Vibration, vol. 2018, Article ID 2518209, 12 pages, 2018.

[22] A. Ansell, "Shotcrete on rock exposed to large-scale blasting," Magazine of Concrete Research, vol. 59, no. 9, pp. 663-671, 2007.

[23] M. Q. Zhang, G. Lu, Z. J. He, J. Y. Liu, and D. H. Luo, "Study of design and construction technology of ultra-large-span tunnel at Badaling Great Wall station," Tunnel Construction, vol. 38, no. 3, pp. 372-381, 2018.

[24] T. Sato, T. Kikuchi, and K. Sugihara, "In-situ experiments on an excavation disturbed zone induced by mechanical excavation in Neogene sedimentary rock at Tono mine, central Japan,” Engineering Geology, vol. 56, no. 1-2, pp. 97-108, 2000.

[25] A. Li, Q. Fang, D. L. Zhang, J. W. Luo, and X. F. Hong, "Blast vibration of a large-span high-speed railway tunnel based on microseismic monitoring," Smart Structures and Systems, vol. 21, no. 5, pp. 561-569, 2018.

[26] M. Khandelwal and T. N. Singh, "Evaluation of blast-induced ground vibration predictors," Soil Dynamics and Earthquake Engineering, vol. 27, no. 2, pp. 116-125, 2007.

[27] C. H. Dowding, "Suggested method for blast vibration monitoring," International Journal of Rock Mechanics and Mining Sciences \& Geomechanics Abstracts, vol. 29, no. 2, pp. 145-156, 1992.

[28] X. Q. Xie, Y. K. Yao, G. Yang, and Y. S. Jia, "Large-scale field experiments on blast-induced vibration and crater in sand medium," International Journal of Geomechanics, vol. 17, no. 8, Article ID 06017001, 2017.

[29] L. P. Li, S. C. Li, Q. S. Zhang, G. Wang, and F. K. Ma, "Monitoring blast excavation of shallow-buried large-span tunnel and vibration reduction technology," Rock and Soil Mechanics, vol. 29, no. 8, pp. 2292-2296, 2008.

[30] G. Mutke, W. Masny, and S. Prusek, "Peak particle velocity as an indicator of dynamic load exerted on the support of underground workings," Acta Geodynamica et Geomaterialia, vol. 13 , no. 4 , pp. $367-378,2016$.

[31] L. Ahmed and A. Ansell, "Structural dynamic and stress wave models for the analysis of shotcrete on rock exposed to blasting," Engineering Structures, vol. 35, no. 2, pp. 11-17, 2012.

[32] E. Dehghani, M. N. Zadeh, and A. Nabizadeh, "Evaluation of seismic behaviour of railway bridges considering track-bridge interaction," Roads and Bridges-Drogi I Mosty, vol. 18, no. 1, pp. 51-66, 2019.

[33] J.-M. Battini and M. Ülker-Kaustell, “A simple finite element to consider the non-linear influence of the ballast on vibrations of railway bridges," Engineering Structures, vol. 33, no. 9, pp. 2597-2602, 2011. 
[34] O. Caglayan, K. Ozakgul, O. Tezer, and E. Uzgider, "Evaluation of a steel railway bridge for dynamic and seismic loads," Journal of Constructional Steel Research, vol. 67, no. 8, pp. 1198-1211, 2011.

[35] F. M. Xu, S. H. Chen, J. Wu, and T. Zhang, "Study on blasting vibration safety standards of shotcrete in underground engineering," Engineering Blasting, vol. 20, no. 5, pp. 32-36, 2014.

[36] A. J. Hulshizer, "Acceptable shock and vibration limits for freshly placed and maturing concrete," ACI Materials Journal, vol. 93, no. 6, pp. 524-533, 1996.

[37] L. Wang, Foundations of Stress Waves, Elsevier Science Ltd., Amsterdam, The Netherlands, 2007.

[38] J. J. Zhou, R. L. Shan, Z. X. Jia, H. H. Geng, Y. F. Zhao, and L. P. Liu, "Study of vibration characteristics of rockbolt and shotcrete structures near the explosion source under blasting load," Rock and Soil Mechanics, vol. 34, no. 8, pp. 2225-2230, 2013.

[39] GB 50086-2001, Specifications for Bolt-Shotcrete Support, China Planning Press, Beijing, China, 2001.

[40] L. Wang, Y. Ding, and L. Yang, "Experimental investigation on dynamic constitutive behavior of aluminum foams by new inverse methods from wave propagation measurements," International Journal of Impact Engineering, vol. 62, no. 10, pp. $48-59,2013$.

[41] W.-b. Lu, Y. Luo, M. Chen, and D.-q. Shu, "An introduction to Chinese safety regulations for blasting vibration," Environmental Earth Sciences, vol. 67, no. 7, pp. 1951-1959, 2012.

[42] B. M. Vandewalle, "The use of steel fibre reinforced shotcrete for the support of mine openings," Journal of the South African Institute of Mining \& Metallurgy, vol. 98, no. 3, pp. 113-120, 1998.

[43] N. Banthia, J.-F. Trottier, D. Beaupre, and D. Wood, "Properties of steel fiber reinforced shotcrete," Canadian Journal of Civil Engineering, vol. 21, no. 4, pp. 564-575, 1994.

[44] L. Cao, Q. Fang, D. Zhang, and T. Chen, "Subway station construction using combined shield and shallow tunnelling method: case study of Gaojiayuan station in Beijing," Tunnelling and Underground Space Technology, vol. 82, pp. 627635, 2018. 


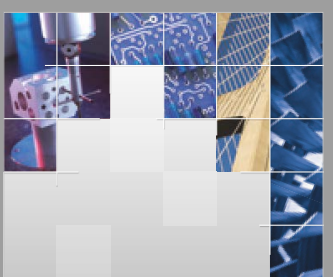

\section{Enfincering}
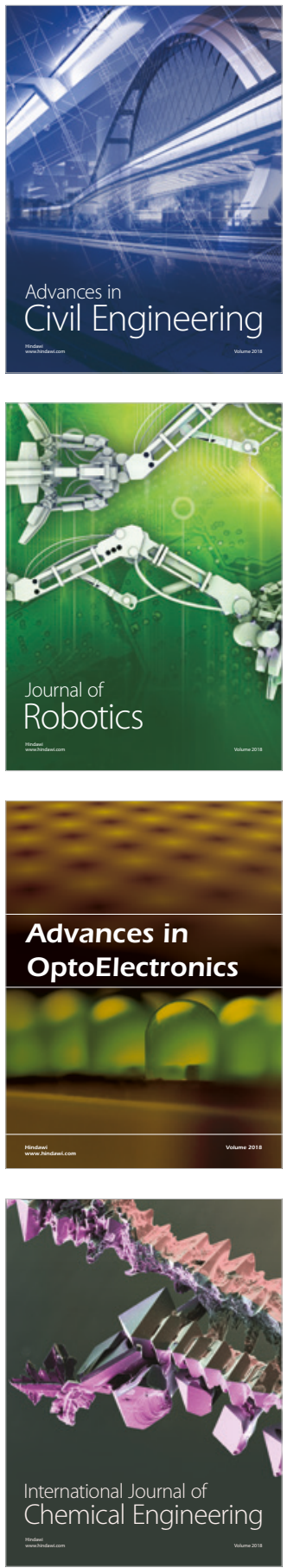

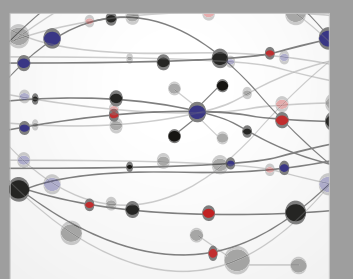

\section{Rotating \\ Machinery}

The Scientific World Journal

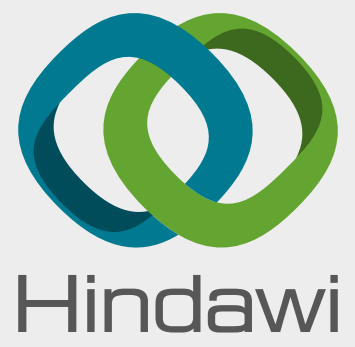

Submit your manuscripts at

www.hindawi.com
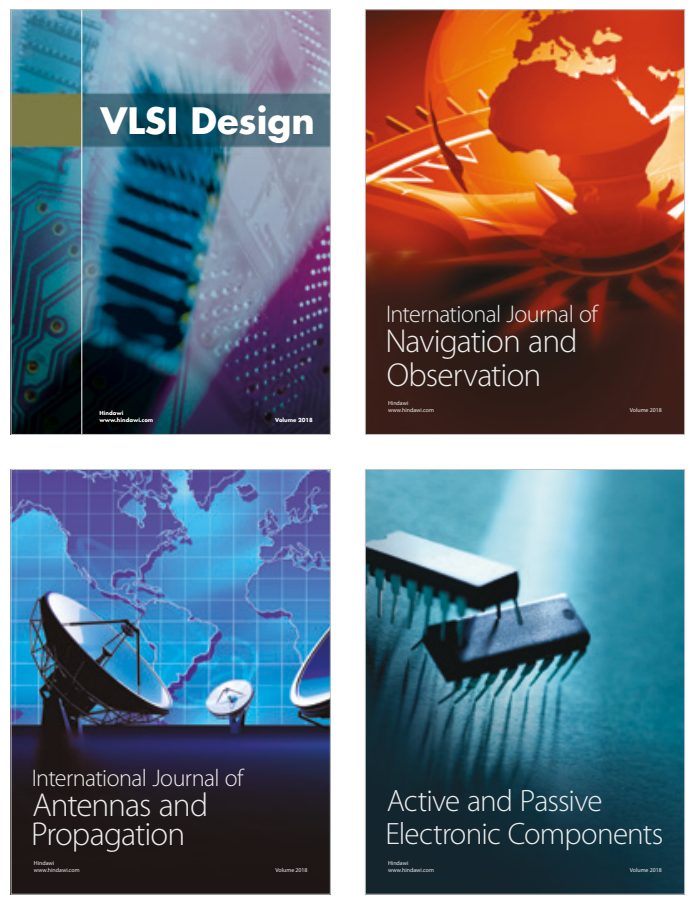
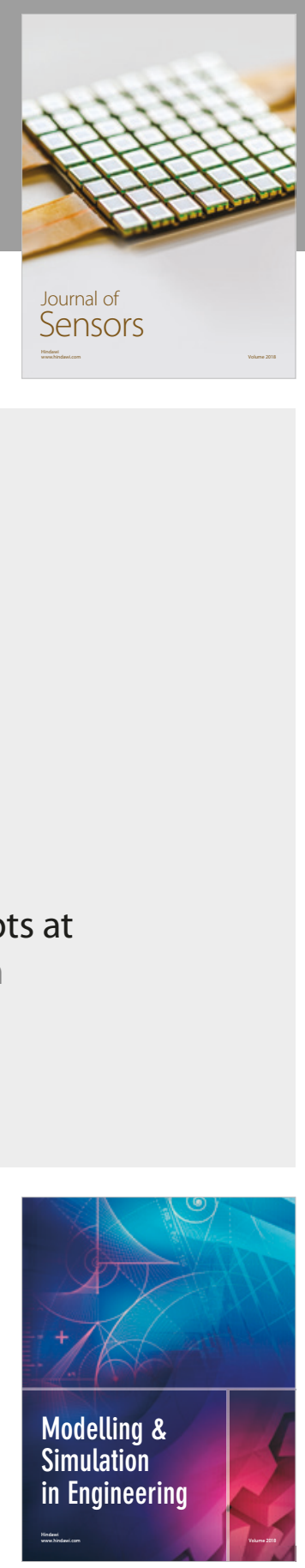

\section{Advances \\ Multimedia}
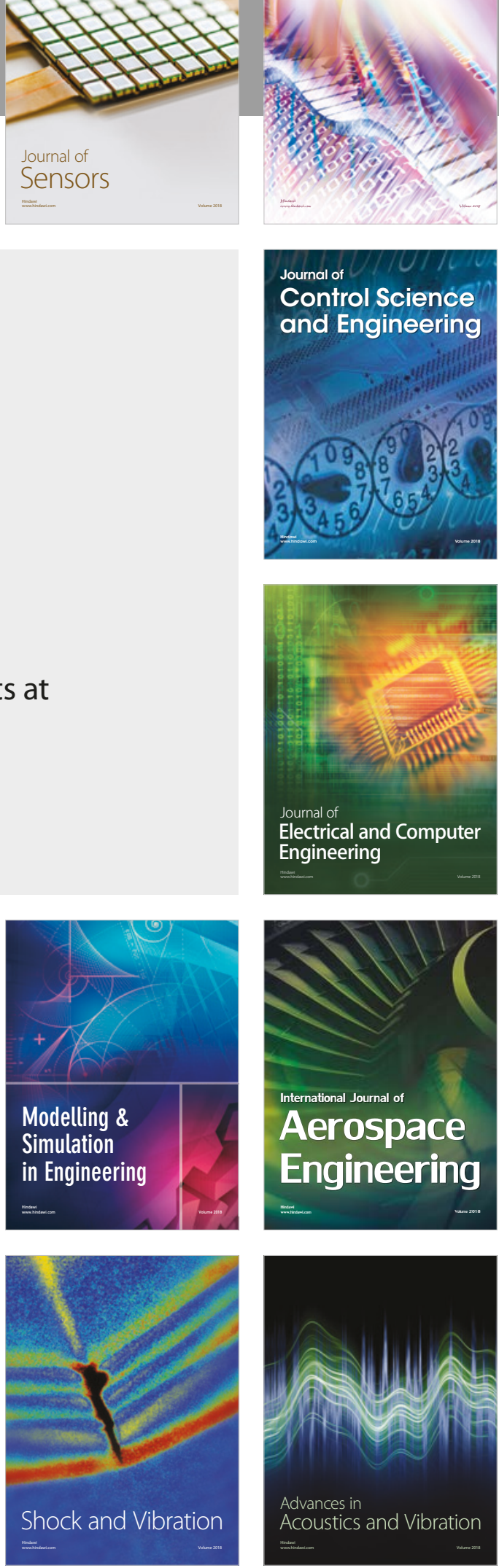